\title{
Parts of the Whole: The Having of Wonderful Ideas: Eleanor Duckworth Introduces Us to Piaget
}

Dorothy Wallace

Dartmouth College, dorothy.wallace@dartmouth.edu

\section{Recommended Citation}

Wallace, Dorothy. "Parts of the Whole: The Having of Wonderful Ideas: Eleanor Duckworth Introduces Us to Piaget." Numeracy 13, Iss. 1 (2020): Article 10. DOI: https://doi.org/10.5038/1936-4660.13.1.10 


\title{
Parts of the Whole: The Having of Wonderful Ideas: Eleanor Duckworth Introduces Us to Piaget
}

\author{
Abstract \\ The small book of essays by Eleanor Duckworth has been a staple of teacher education for decades, \\ serving as a bridge between Piaget's observations of infants and the needs of the classroom. As her \\ examples tend to be of young children, we consider more general ideas in the context of older grades and \\ higher education. Several of her insights are discussed with an eye to application in the field of \\ quantitative education, highlighting the need to integrate issues of pedagogy with those of content.

\section{Keywords} \\ mathematics, quantitative reasoning, quantitative literacy, Duckworth, Piaget

\section{Creative Commons License} \\ cc) (i) (8) \\ This work is licensed under a Creative Commons Attribution-Noncommercial 4.0 License

\section{Cover Page Footnote} \\ Dorothy Wallace, Contributing Editor of Numeracy, is a professor of mathematics at Dartmouth. She has \\ broad background in many kinds of mathematics, with numerous publications in pure, applied, and \\ educational topics. Her recent research papers in mathematical biology include some 30 undergraduates \\ among her coauthors. She was a charter board member of the National Numeracy Network and was a \\ founding co-editor of this journal.
}




\title{
Parts of the Whole
}

\author{
A Column by D. Wallace
}

The problem of how best to improve the numeracy of a society is a thorny one, addressing the learning process of a single student but rising in scale to include the management and alteration of an entire system of education. With the issue of quantitative literacy always in mind, this column will consider various aspects of the systemic workings of education: the forces acting on classrooms, teachers, and students and mechanisms of both stasis and change. With the issues of volume 9, the column has grown to include thoughts on pedagogy, in addition to continuing to explore strategies for systemic change in quantitative education.

\section{The Having of Wonderful Ideas: Eleanor Duckworth Introduces Us to Piaget}

For many years the teaching seminar for mathematics graduate students at Dartmouth featured The Having of Wonderful Ideas as required reading (Duckworth, 1987). After taking graduate courses with the famous psychologist Piaget, Duckworth continued her career in education, first in developing a science curriculum for children, later as an educator of other teachers. Throughout her career she struggled with making Piaget's observations of infant learning relevant to teaching young children learning science and educating adults learning to teach. Her account of this effort is full of useful observations that can, with a bit of work, transfer to the college classroom.

I will treat this column as an opportunity to respond to some favorite quotes from her book with the issues of teaching quantitative reasoning in mind. I will look at only a few of her many observations, italicized in the text below, and leave the reader to investigate the rest of this delightful volume.

\section{The Clinical Interview}

The main tool Duckworth uses to get inside a child's head is the clinical interview, a method developed by Piaget. It is a conversation between the child and the interviewer in which the child is asked a question and his or her answers are probed with further questions. Importantly, there is to be no attempt to influence these answers in the direction of a preferred answer, as the goal is not to teach anything but to learn how the child thinks. Interview questions must be carefully designed to give no hints of the right answer. Using this method, Piaget uncovered a rich thought process undertaken by the children that could not be revealed by the usual testing format. 
Duckworth is adept at conducting clinical interviews with children, and she offers detailed transcripts of several in her book. Given a problem to solve that is chosen to be a complex task for their level, the children exhibit a variety of approaches and have many surprising insights that are extracted via the interview process. Duckworth's book is about leveraging the educational value of these "wonderful ideas."

\section{Knowing the Right Answer}

... of all the virtues related to intellectual functioning, the most passive is the virtue of knowing the right answer. Knowing the right answer requires no decisions, carries no risks, and makes no demands. It is automatic. It is thoughtless. (Duckworth 1987)

In the quantitative reasoning community, there is a lot of talk about "critical thinking." Duckworth here makes two points. One is that, as soon as the right answer is reached, thinking stops. Furthermore, knowing the right answer to a question is no guarantee that critical thinking happened. Conversely, researchers intent on solving a problem in their domain of expertise know that a lot of thinking can go into a problem without getting to any solution, let alone a correct one. As an example, we quote a problem from an online collection of sample problems in quantitative reasoning for the Graduate Record Examination given by the Educational Testing Service (ETS n.d., Quantitative Comparison).

A university admitted 100 students who transferred from other institutions. Of these students, 34 transferred from two-year community colleges, 25 transferred from private four-year institutions, and the rest transferred from public four-year institutions. If two different students are to be selected at random from the 100 students, what is the probability that both students selected will be students who transferred from two-year community colleges?

The test taker is asked to give the answer as a fraction. One could imagine a variety of approaches to this problem. Here are three:

1. In statistics we learned that when drawing a particular color ticket from a box without replacement, there is a formula for multiple draws. If $f$ is the number of red tickets and there are $N$ tickets in the box, the chance of drawing a red ticket is $f / N$. The chance of drawing two red tickets is $(f / N) *((f-1) /(N-1))$. I don't remember why. But this problem seems similar.

2. Choosing students at random from this population sounds like the two choices are almost independent events. I know that the probability of two independent events is the product of the individual probabilities. That would give $(f / N)^{2}$. This doesn't seem quite right but I'm sure it is close.

3. The chance that the first student is a 2 -year transfer is $34 / 100$. The second student is one of 33 remaining 2 -year students in a population of 99 . I know that the probability of two 
independent events is the product of the individual probabilities. So this gives (34/ $100) *(33 / 99)$.

In this example, answer 1 and answer 3 are the same and cannot be distinguished on a test of this sort. Yet answer 1 is the result of memorization without understanding, whereas answer 3 is well thought out. The right answer to this question indicates that the person has been exposed to the subject, but it does not guarantee that thinking has happened.

Answer 2 is quite interesting because, although it is wrong, it is the result of a reasonable approximation of the problem. Some thinking has happened. In addition, there is an indication that the person doesn't quite trust their answer. In other words, there is a self-critical aspect as well. The person giving this answer has an approach that will give reasonable, if not perfect, answers in many other situations.

Duckworth sums this up nicely:

But no tester will ever know and no score will ever reveal whether the right answer was a triumph of imagination and intellectual daring, or whether the child knew the right answer all along. In addition, the more time the child spends on figuring things out on the test, the less time there is for filling in the right answers; that is, the more you actually think to get the right answer on an intelligence test, the less intelligent the results will look. (Duckworth 1987)

As we continue to build assessment devices for quantitative reasoning, Eleanor Duckworth's comments stand as a warning. We can easily create assessment tools that encourage the educational system to destroy the critical thinking we want students to develop. We must not forget that assessment tools don't just observe the state of the system; they drive it. The virtue of getting a good test score is ultimately a short-lived triumph. Again, I will quote Duckworth,

The virtues involved in not knowing are the ones that really count in the long run. What you do about what you don't know is, in the final analysis, what determines what you will ultimately know. (Duckworth 1987)

\section{Concepts}

'Concept' usually seemed to imply a noun, and when I'm trying to state things I would like children to know, I usually can't state them as nouns. (Duckworth 1987)

Duckworth spends considerable effort deconstructing what it means to know something. Her discussion is thick with illuminating examples. One would imagine that, before teaching a concept, one would be very clear on what that concept was. Once again let us use an example from the GRE examination to see how confusing this question actually is (ETS n.d., Numeric Entry). Two quantities 
are described algebraically: $A=x^{2}+1$, and $B=2 x-1$. Which of the following is true? The four choices offered are: (A) $A>B$; (B) $B>A$; (C) $A=$ $B$; (D) Not enough information to tell. Let's look at some possible lines of reasoning.

1. Check $x=1,2,3$. For these, $A>B$, so I guess that this is always true.

2. Look at the difference between $A$ and $B$. This is a quadratic and I can compute the roots. However, the discriminant is negative so there are no real roots. Therefore, one is always larger than the other, so check any value of $x$. I conclude that $A>B$.

3. Look at the difference between $A$ and $B$. This is a quadratic and I know that it takes different values for different $x$. Also, not all the terms are positive, so in principle the expression could be a negative number. I think I don't have enough information to tell. I choose D.

4. Quadratics grow faster than linear functions, so I know that eventually $A>B$. I'll check a couple of small values of $x$. That seems right. I think $A>B$.

Clearly the four answers here reflect people who use their algebra differently. What they know about algebra translates into what they do when confronted with a problem. Person 1 knows how to plug a number into an algebraic formula, and also knows that this can give insight even if you can't deal with the question any other way. Person 2 understands how to use the quadratic formula and what it means. Person 3 understands that the signs of the terms might make the whole polynomial change sign. Arguably, this person is more sophisticated than Person 1 yet gets the answer wrong. Person 4 understands the overall growth pattern of different classes of functions and makes an incorrect generalization to get a correct answer.

No matter which of these four types of understanding one might want students to have, this problem fails to require exactly that one. As educators, we are quite unclear about what we want from algebra students (Wallace, 2011). We pose problems that we hope will distinguish those that "have" the concept from those that do not. We make the classic logical fallacy of assuming that being able to do the problem indicates understanding of the concept being taught. The example shows that this close relationship is very hard to achieve in practice.

I don't know what the assessment goal was of this particular question on the GRE exam. But Duckworth offers another way to look at it. We could ask: What is it we want students to do when faced with a problem like this? And then we have to test in such a way that we can see what they did to choose an answer.

\section{Intellectual Development}

It is a truism that all children in their first and second years make incredible intellectual advances .... Why does the intellectual development of vast numbers of children then slow down? Why do so few continue to have their own wonderful ideas? (Duckworth 1987) 
Duckworth describes a science curriculum for children that she worked on, its goals designed with the long run in mind. For example, the goals of a making and using a simple microscope included: awareness of the microscopic world, the ability to make a tool to see it, the fun of looking through the lens, the importance of sharing what you see with others, and the realization that it is good to be able to follow printed directions. No standardized test can reveal whether these goals have been met. Yet these sorts of activities are likely to produce inquisitive minds full of wonderful ideas. Duckworth summarizes:

The difference can best be characterized by saying that the unexpected is valued. (Duckworth 1987)

For Duckworth, this is the crux of the problem. Without the spark of creativity that she calls "intellectual alertness" in students, educational objectives will only result in a set of tasks to be surmounted and then forgotten. Beyond assisting students to answer questions that no student has thought to ask, quantitative reasoning should become a useful tool for students to have, test and explore their own wonderful ideas.

\section{Teaching and Research}

Listening to Duckworth attempting to make Piaget relevant in the classroom leads to the realization that most of our failures in pedagogy stem from our inability to see inside another person's head. If we could really see how our students are understanding material, whether they are bored, and what excites them, we could do a better job making our quantitative reasoning efforts stick. If we could see the ideas they are having, which we often make them put aside for the sake of efficiency, we might encourage them to pursue those ideas instead of doing the problems at the end of the chapter. A whole field of research is open here bearing research results that would be welcome in this journal. The tools of quantitative reasoning are powerful and should be put in the hands of people having wonderful ideas.

\section{References}

Duckworth, Eleanor. 1987. "The Having of Wonderful Ideas" and Other Essays on Teaching and Learning. Teacher's College Press.

Educational Testing Service. n.d. "GRE General Test: Quantitative Reasoning, Sample Questions."

https://www.ets.org/gre/institutions/about/general/quantitative_reasoning_sa mple questions/ (Last accessed 12/24/2019).

Wallace, Dorothy. 2011. "Parts of the Whole: An Algebra Lesson." Numeracy 4(2): Article 10. DOI: http://dx.doi.org/10.5038/1936-4660.4.2.10. 